\title{
Haemangiosarcoma of the os penis in a dog: The most common neoplasm of the canine penis
}

\begin{tabular}{|c|c|}
\hline \multicolumn{2}{|c|}{$\begin{array}{l}\text { Authors: } \\
\text { Richard K. Burchell } \\
\text { Robert M. Kirberger }^{1} \\
\text { Drienie D. (Didi) Janse van } \\
\text { Rensburg }\end{array}$} \\
\hline $\begin{array}{l}\text { Affiliations: } \\
{ }^{1} \text { Department } 0 \\
\text { Animal Clinical } \\
\text { University of P } \\
\text { South Africa }\end{array}$ & $\begin{array}{l}\text { f Companion } \\
\text { Studies, } \\
\text { retoria, }\end{array}$ \\
\hline $\begin{array}{l}{ }^{2} \text { Department } \\
\text { Studies, Unive } \\
\text { Pretoria, South }\end{array}$ & $\begin{array}{l}\text { f Paraclinical } \\
\text { sity of } \\
\text { Africa }\end{array}$ \\
\hline $\begin{array}{l}\text { Corresponden } \\
\text { Richard Burch }\end{array}$ & $\begin{array}{l}\text { ce to: } \\
\text { ll }\end{array}$ \\
\hline $\begin{array}{l}\text { Email: } \\
\text { rkburchell@gn }\end{array}$ & ail.com \\
\hline $\begin{array}{l}\text { Postal address } \\
\text { Private Bag XO } \\
\text { Onderstepoor } \\
\text { South Africa }\end{array}$ & $\begin{array}{l}: \\
4, \\
0110,\end{array}$ \\
\hline $\begin{array}{l}\text { Dates: } \\
\text { Received: } 01 \mathrm{~A} \\
\text { Accepted: } 02 \mathrm{~N} \\
\text { Published: } 21 \\
\text { Republised: } 10\end{array}$ & $\begin{array}{l}\text { ug. } 2013 \\
\text { lov. } 2013 \\
\text { Aug. } 2014 \\
\text { Sept. } 2014\end{array}$ \\
\hline $\begin{array}{l}\text { How to cite th } \\
\text { Burchell, R.K., } \\
\text { R.M. \& Van Re } \\
\text { 2014, 'Haemar } \\
\text { of the os penis } \\
\text { most common } \\
\text { the canine per } \\
\text { the South Afric } \\
\text { Association } 85 \\
\text { \#1092, } 4 \text { page } \\
\text { dx.doi.org/10. } \\
\text { v85i1.1092 }\end{array}$ & $\begin{array}{l}\text { is article: } \\
\text { Kirberger, } \\
\text { isberg, D.D., } \\
\text { igiosarcoma } \\
\text { in a dog: The } \\
\text { neoplasm of } \\
\text { is', Journal of } \\
\text { an Veterinary } \\
\text { (1), Art. } \\
\text { http:// } \\
\text { 4102/jsava. }\end{array}$ \\
\hline $\begin{array}{l}\text { Note: } \\
\text { This article wa } \\
\text { with the corre } \\
\text { the third auth }\end{array}$ & $\begin{array}{l}\text { republished } \\
\text { t spelling of } \\
\text { r's surname. }\end{array}$ \\
\hline $\begin{array}{l}\text { Copyright: } \\
\text { (C) 2014. The A } \\
\text { Licensee: AOSI } \\
\text { OpenJournals. } \\
\text { is licensed und } \\
\text { Creative Comn } \\
\text { Attribution Lic }\end{array}$ & $\begin{array}{l}\text { uthors. } \\
\text { S } \\
\text { This work } \\
\text { er the } \\
\text { lons } \\
\text { ense. }\end{array}$ \\
\hline Read online: & $\begin{array}{l}\text { Scan this QR } \\
\text { code with your } \\
\text { smart phone or } \\
\text { mobile device } \\
\text { to read online. }\end{array}$ \\
\hline
\end{tabular}

A castrated 9-year-old intact male boerboel cross-breed dog was presented with a month-long history of stranguria. On physical examination, a mass was noted at the caudal extremity of the os penis. Haematology, serum chemistry and urinalysis were all unremarkable. Abdominal and urethral ultrasound demonstrated an enlarged bladder and a dilated urethra, which was followed to the caudal extremity of the os penis. A hyperechoic, roughly spherical, vascularised mass was noted at the caudal os penis, which resulted in obstruction of the penile urethra. Radiographs demonstrated a soft tissue mass with osteolysis of the os penis. Cytology suggested an osteosarcoma. Treatment included amputation of the penis and adjuvant doxorubicin with carboplatin. Histopathology of the penis confirmed a haemangiosarcoma. The patient survived for 20 months. This is only the second published case report describing a penile haemangiosarcoma, and the first published report demonstrating the treatment and outcome of a case of haemangiosarcoma of the os penis. Based on published and unpublished reports, haemangiosarcoma appears to be the most common neoplasm of the canine penis.

\section{Introduction}

Neoplasia of the canine os penis is uncommon. A mesenchymoma (Root, Kustritz \& Fick 2007), two osteosarcomas (Bleier, Lewitschek \& Reinacher 2003; Peppler et al. 2009), an ossifying fibroma (Mirkovic, Schmon \& Allen 2004) and a multilobular osteochondrosarcoma (Webb et al. 2009) have previously been reported. Canine haemangiosarcoma is a malignant neoplasm of multipotent bone marrow cells accounting for $2 \%$ of all canine neoplasms (Bergman 2010; Smith 2003). Haemangiosarcoma most commonly occurs in the spleen, but has been described in many other locations (Bergman 2010). A single published case report (Marolf et al. 2006) and two unpublished senior seminar presentations at Cornell University (Becker 2009; Doherty 2007) describing penile bone haemangiosarcoma and one report of a primary prostatic haemangiosarcoma (Della Santa et al. 2008) were found. No peer-reviewed information is available regarding the treatment and outcome of penile haemangiosarcoma. The prognosis for haemangiosarcoma is generally poor, with the exception of dermal haemangiosarcoma, where the median survival time is approximately 780 days (Bergman 2010), and lingual haemangiosarcoma, where a median survival time of 553 days has been described in a study of 20 dogs (Burton, Powers \& Biller 2012).

\section{Case history}

A 9-year-old intact boerboel cross-breed dog was presented with a month-long history of stranguria and pollikuria. The patient had been examined by the referring veterinarian and had been treated with antibiotics. On clinical evaluation, a large bladder and a spherical swelling at the caudal aspect of the os penis were detected by palpation. Routine urinalysis, haematology and serum biochemistry were unremarkable. Abdominal and penile ultrasound was performed (Siemens Sonoline Omnia, Siemens, Germany). Abdominally, the only abnormalities detected were a distended bladder and pelvic urethra. The urethra was tracked transcutaneously along the length of the penis up to the level of the os penis where an extramural obstructive, roughly spherical $13.7 \mathrm{~mm}$ by $14.3 \mathrm{~mm}$ mass was seen. It was completely compressing the urethral lumen, resulting in distension of the urethra caudal to the mass (Figure 1). The mass was hyperechoic relative to the adjacent soft tissue and a number of irregularly shaped small hyperechoic specks were seen with associated distal acoustic shadows indicative of mineralisation (Figure 1). The mass appeared to involve the parenchyma of the penis and was suspected to have arisen extramurally, invading the urethral lumen. Colour flow Doppler (Siemens Sonoline Omnia, Siemens, Germany) indicated significant vascularity within the mass and on its periphery. The surface of the os penis was irregular and undulating with varying thickness, indicative of a periosteal reaction and lysis. A neoplasm of the penis, the os penis or surrounding tissue was suspected. Fine needle aspiration of the mass and cytology indicated a poorly differentiated sarcoma, ostensibly an osteosarcoma. Metastatic lung and lateral radiographs centred and collimated over the os penis were made. Thoracic views were normal. Radiographs of the os penis demonstrated a single, spherical soft 
tissue opacity located over the caudal half of the os penis. It was associated with moderate lysis of the os penis and a sparse brush-like to sunburst periosteal reaction (Figure 2).

Urethroscopy was performed. At the caudal limit of the os penis the urethra was completely occluded by the mass, preventing futher caudal examination. The urethra overlying the mass was intact, contrary to what was suspected based on ultrasound findings. Transurethral biopsies were obtained under general anaesthesia and submitted for histopathology. There was minimal bleeding during the procedure. Spindle-like sarcoma cells were present and an osteosarcoma was suspected, but lack of osteoid obfuscated the definitive diagnosis. Complete surgical ablation of the penis and a scrotal urethrostomy were performed and the whole penis was submitted for histological evaluation. A proliferation of fairly monomorphic spindle-shaped neoplastic cells infiltrated the bulbus spongiosus, invaded normal muscle tissue and bone in places, and extended to the surgical margins. The mass was densely cellular, occasionally separated by cavernous vascular spaces that were lined with similar neoplastic cells. There were intervening thick bands of fibrovascular connective tissue entrapping fibroblasts and normal bone (Figure 3a). The cells were large and pleomorphic with indistinct cytoplasmic margins and moderate amounts of finely granular to vacuolar amphophilic cytoplasm (Figure 3b). Mitoses ranged from one to six per high power field. The neoplastic cells were separated by a fibrillar to homogenous eosinophilic extracellular matrix (basement membrane material) in places. Haemangiosarcoma was suspected, but a telangiectatic osteosarcoma was a possible differential diagnosis. Special stains were applied to confirm the diagnosis. Initial staining with polyclonal Factor VIII (A0082, Dako, USA) antibodies showed a weakly positive reaction. This was believed to be consistent with a well-vascularised osteosarcoma. Notwithstanding this finding, the histological features were more consistent with a haemangiosarcoma and, thus, further immunohistochemical studies and electron microscopy were performed. All the neoplastic cells, including those lining the cavernous spaces, showed cytoplasmic, granular positive immunohistochemical labelling with monoclonal CD31 (M0823, Dako, USA). On subsequent staining, the cells labelled positively with polyclonal Factor VIII (A0082, Dako, USA) antibodies (Figure 4). On electron microscopy, the neoplastic cells had tight junctions and basement membrane in areas, which was consistent with endothelial cells.

A final diagnosis of haemangiosarcoma was reached. Echocardiography was performed prior to chemotherapy to assess the right atrium for a possible primary mass and to assess the cardiac function prior to doxorubicin administration. Echocardiographic appraisal included standard 2D imaging measurements and Doppler interrogation of transvalvular flows. The echocardiographic study was within normal limits. Chemotherapy was instituted on the day of suture removal. The patient was treated with three doses of doxorubicin $\left(30 \mathrm{mg} / \mathrm{m}^{2}\right)$ and carboplatin $\left(300 \mathrm{mg} / \mathrm{m}^{2}\right)$, alternating between

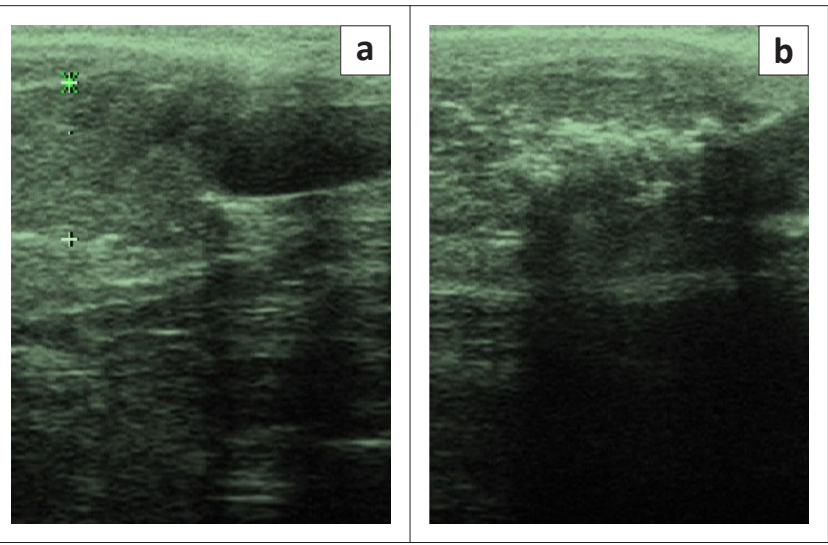

Source: Onderstepoort Veterinary Academic Hospital, Faculty of Veterinary Science, University of Pretoria

Note: Cranial is to the left.

FIGURE 1: Sagittal diagnostic ultrasound images of the caudal os penis region, (a) the obstructive haemangiosarcoma mass between the cursors is located cranially to the anechoic dilated urethra and (b) slightly different imaging plane showing the irregular hyperechoic os penis remnants with some acoustic shadowing within the haemangiosarcoma.

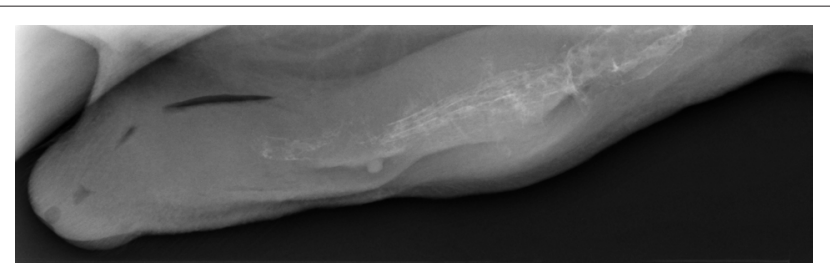

Source: Onderstepoort Veterinary Academic Hospital, Faculty of Veterinary Science, University of Pretoria

Note: Image shows permeative lysis and some faint brush-like periosteal reactions of the os penis.

FIGURE 2: Lateral skyline view of the os penis and prepuce.

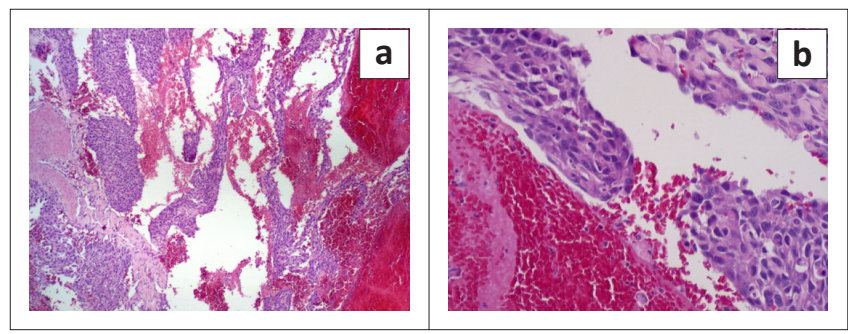

Source: Department of Paraclinical Studies, Faculty of Veterinary Science, University of Pretoria

FIGURE 3: Photomicrographs of the mass in the os penis, (a) numerous cavernous blood-filled spaces seen that are lined with monomorphic neoplastic cells (40 x magnification, HE staining) and (b) the mass is densely packed with large cells with indistinct cytoplasmic margins and moderate amounts of finely granular to vacuolar amphophilic cytoplasm and basophilic nuclei ( $200 \mathrm{x}$ magnification, HE staining).

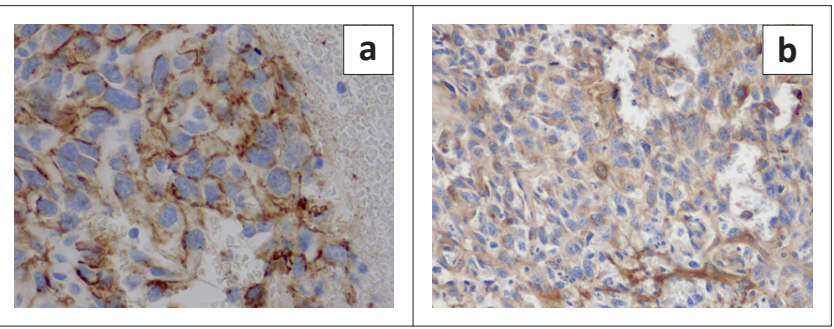

Source: Department of Paraclinical Studies, Faculty of Veterinary Science, University of Pretoria

FIGURE 4: Photomicrographs of the mass of the os penis (200 x magnification), (a) Neoplastic cells labelled with CD31 monoclonal antibody showing positive cytoplasmic granular labelling. The cells line the cavernous spaces and (b) labelled with polyclonal Factor VIII antibody also showing positive cytoplasmic granular labelling on immunohistochemistry. 
the two drugs every three weeks according to the protocol promulgated by Kent et al. (2004). This protocol was initiated after the initial immunohistochemical findings suggested an osteosarcoma. Based on the preponderance of evidence at the time, osteosarcoma was considered more plausible and, thus, the chemotherapy protocol was tailored accordingly. Haematology and serum creatinine were evaluated prior to each treatment, and the owners kept a diary documenting episodes of vomiting, diarrhoea and anorexia. No adverse effects were noted during the chemotherapy protocol. At a six-month check-up the patient was judged to be in complete remission. Twenty months after surgery the owners presented the patient to the referring veterinarian after he collapsed, and they requested euthanasia. A post-mortem was declined.

\section{Discussion}

This case demonstrates the diagnostic value of ultrasound in the appraisal of the lower urinary tract. Whilst radiographs demonstrated the location of the lesion, a contrast study would be required to delineate the obliteration of the urethra and demonstrate the obstructive nature of the lesion. In addition, the origin of the mass was ultrasonographically determined to be arising from the penis as opposed to the urethra, which narrowed the list of differential diagnoses to neoplasms expected to occur in this region. However, ultrasonography lacks the resolution that was necessary to determine whether or not the neoplasm had perforated the urethral lumen. This highlights the need for multimodal non-invasive diagnostic tests with which to provide a comprehensive assessment of neoplasms. Urethroscopy refuted the notion that the mass had perforated the urethra and was able to provide diagnostic samples, which assisted in the pre-surgical assessment. The biological aggression of the mass on histopathology indicated that an aggressive surgical procedure was required.

In addition, this report emphasises the need for special staining in the case of undifferentiated neoplasms since this may be of prognostic significance. In this case, the initial factor VIII staining was equivocal. A more sensitive and specific marker of endothelial cells is CD31 (Jennings, Miller \& Ramos-Vara 2012). Our findings confirm the improved sensitivity of CD31 in labelling endothelial cells. Therefore, clinicians should interpret all of the histological findings together and discuss additional immunohistochemical markers with the pathologist where there is uncertainty. Osteosarcoma has many biological variants, including a telangiectatic form that has scant osteoid and forms cavernous spaces that may mimic a haemangiosarcoma (Brellou et al. 2004). Whilst the subclass of osteosarcoma does not appear to affect the prognosis (Kirpensteijn et al. 2002), different biological behaviours would be expected for haemangiosarcoma compared with osteosarcoma, and thus, differentiation of these neoplasms becomes important in establishing expected outcomes. This is particularly relevant in the case of osteosarcoma versus haemangiosarcoma, given the fact that echocardiography is considered a necessary pre-surgical step in haemangiosarcoma but not in osteosarcoma. There is some discrepancy in the literature regarding the true incidence of cardiac involvement in canine haemangiosarcoma, with Waters et al. (1988) and Boston et al. (2011) reporting incidences of $25 \%$ and $8.7 \%$ respectively. Notwithstanding this disparity, cardiac involvement presents an additional treatment challenge and worsens the prognosis (Wiesse et al. 2005) and therefore should be considered part of the staging of a haemangiosarcoma. Therefore, given the current evidence and the fact that there are more cases of haemangiosarcoma involving the penis described than osteosarcoma, clinicians should consider echocardiography prior to surgical ablation, unless there is firm histological evidence, such as osteoid deposition, that the mass is an osteosarcoma.

The survival time of this patient greatly exceeded what was initially expected based on the biological aggression of the neoplasm apparent on histopathology. This is perhaps due to the fact that direct seeding of a body cavity was impossible in this location as is the case in splenic or cardiac haemangiosarcoma. The generous vascularity of the penis would be a sensible counter argument and therefore this observation remains speculative. Clinicians should not, therefore, extrapolate the outcome of a neoplasm in one anatomical location to another. Case reports such as these are often the only available literature regarding rare presentations of common diseases that can guide clinicians (albeit in a limited capacity) in making decisions. The two unpublished reports (Becker 2009; Doherty 2007) only provided five-month follow up data, with one patient having succumbed to metastatic disease (Becker 2009) and the other showing no signs of metastasis at five months post surgery (Doherty 2007). The growing body of literature regarding neoplasia of the penile bone indicates that haemangiosarcoma is the most common neoplasm involving the os penis and clinicians should be aware of penile bone neoplasia as a cause of extramural urinary obstruction in the dog.

\section{Acknowledgements Competing interests}

The authors declare that they have no financial or personal relationship(s) which may have inappropriately influenced them in writing this article.

\section{Authors' contributions}

R.B. (University of Pretoria) was the veterinary clinician responsible for this clinical case and wrote the case report. D.D.v.R. (University of Pretoria) did the pathology descriptions and reviewed the article content. R.M.K. (University of Pretoria) gave intellectual and practical contributions regarding the imaging study and writing description, and made general comments regarding the overall thrust of the manuscript.

\section{References}

Bergman, P., 2010, 'Hemangiosarcoma', in S.J. Ettinger \& E.C. Feldman (eds.), Textbook of Veterinary Internal Medicine, 7th edn., pp. 2175-2180, Saunders, Philadelphia. 
Becker, L., 2009, 'Hemangiosarcoma of the penis in a German shepherd dog', Senior seminars, Cornell University, viewed 02 September 2013, from http://hdl.handle. net/1813/12867

Bleier, T., Lewitschek, H.P. \& Reinacher, M., 2003, 'Canine osteosarcoma of the penile bone', Journal of Veterinary Medicine. A Physiology, Pathology, Clinical Medicine 50 397-398.

Boston, S.E., Higginson, G. \& Monteith, G., 2011, 'Concurrent splenic and right atrial mass at presentation in dogs with HSA: A retrospective study', Journal of the American Animal Hospital Association 47, 336-341.

Brellou, G., Papaioannou, N., Patsikas, M., Polizopoulou, Z. \& Vlemmas, I., 2004, 'Vertebral telangiectatic osteosarcoma in a dog', Veterinary Clinical Pathology 33, 159-162.

Burton, J.H., Powers, B.E. \& Biller, B.J., 2012, 'Clinical outcome in 20 cases of lingual hemangiosarcoma in dogs: 1996-2011', Veterinary and Comparative Oncology, viewed Sept. 2013, from http://dx/doi.org/10.1111/j.1476-5829.2012.00351.x

Della Santa, D., Dandrieux, J., Psalla, D., Gorgas, D., Lang, J., Geissbuehler, U. \& et al. 2008 'Primary prostatic haemangiosarcoma causing severe haematuria in a dog', Journal of Small Animal Practice 49, 249-51.

Doherty, P., 2007, 'Hemangiosarcoma of the penis in a Belgian Shepherd dog', Senior seminars, Cornell University, viewed 02 Sept. 2013, from http://hdl.handle. net/1813/13297.

Jennings, R.N., Miller, M.A. \& Ramos-Vara, J.A., 2012, 'Comparison of CD34, CD31, and factor VIII-related antigen immunohistochemical expression in feline vascular neoplasms and CD34 expression in feline nonvascular neoplasms', Veterinary Pathology 49, 532-537.

Kent, M.S., Strom, A., London, C.A. \& Seguin, B., 2004, 'Alternating carboplatin and doxorubicin as adjunctive chemotherapy to amputation or limb-sparing surgery in
the treatment of appendicular osteosarcoma in dogs', Journal of Veterinary Internal Medicine 18, 540-544.
Kirpensteijn, J., Kik, M., Rutterman, G.R. \& Teske, E., 2002, 'Prognostic significance of a new histological grading system for canine osteosarcoma', Veterinary Pathology 39, 240-246.

Marolf, A., Specht, A., Thompson, M. \& Castleman, W., 2006, 'Imaging diagnosis: Penile hemangiosarcoma', Veterinary Radiology and Ultrasound 47, 474-475.

Mirkovic, T.K., Shmon, C.L. \& Allen, A.L., 2004, 'Urinary obstruction secondary to an ossifying fibroma of the os penis in a dog', Journal of the American Animal Hospital Association 40, 152-156.

Peppler, C., Weissert, D., Kappe, E., Klum, C., Kramer, M., Reinacher, M. \& et al. 2009 'Osteosarcoma of the penile bone (os penis) in a dog', Australian Veterinary Journal 87, 52-55.

Root, M., Kustritz, M.V. \& Fick, J.L., 2007, 'Theriogenology question of the month: Neoplasia of the os penis', Journal of the American Animal Hospital Association 230, 197-198.

Smith, A.N., 2003, 'Hemangiosarcoma in dogs and cats', Veterinary Clinics of North America: Small Animal Practice 33, 533-552.

Waters, D.J., Caywood, D.D. \& Hayden, D.W., 1988, 'Metastatic pattern in dogs with splenic haemangiosarcoma: Clinical implications', Journal of Small Animal Practice 29, 805-814.

Webb, J.A., Liptak, J.M., Hewitt, S.A. \& Vince, A.R., 2009, 'Multilobular osteochondroma of the os penis in a dog', Canadian Veterinary Journal 50 , 81-84.

Wiesse, C., Soares, N., Beal, M.W., Steffy, M.A., Dobratz, K.J. \& Henry, C.J., 2005, 'Survival times in dogs with right atrial hemangiosarcoma treated by means of surgical resection with or without adjuvant chemotherapy: 23 Cases (1986-2000)', Journal of the American Veterinary Medical Association 15, 575-579. 